\section{Re: Effects of Implementing a Comprehensive Opioid Reduction Protocol on Overall Opioid Prescribing Among Patients with Chronic, Non-Cancer Pain in a Rural Family Medicine Clinic: A Controlled Crossover Trial}

To the Editor: Stack et $\mathrm{al}^{1}$ describe a comprehensive opioid reduction protocol in patients with chronic noncancer pain conducted by Family Medicine providers in a rural community. Although the authors describe a multifaceted approach with medical and psychoeducational components, 1 key element is missing: the patient experience. Exclusion of patient function is mentioned as a limitation of the study, but the importance of the patient perspective as it pertains to opioid reduction, functional assessment, and pain is minimized. Comprehensive care of the patient with chronic noncancer pain should incorporate a patient-centered plan, which must include functional assessment and long-term followup.

Opioids are dangerous medications with myriad side effects. ${ }^{2}$ Tapering opioids too quickly can result in withdrawal symptoms and return of pain. Implementation of a functional pain scale, like the Brief Pain Inventory, ${ }^{3}$ would objectively assess both the patients' experiences and the protocol's sustainability. Although this tool was originally constructed to assess patients with cancerrelated pain, its use has been extended to chronic noncancer pain. ${ }^{3}$ Relapse after opioid tapering is not uncommon, ${ }^{4}$ and therefore followup is imperative. Including a 12-month followup after the intervention would help establish the protocol's sustainability. It is one thing to reduce milligram morphine equivalents (MME), but it is another entirely to reduce MME while maintaining functional status.

When decreasing opioid doses, primary care physicians should advocate for the path of least harm while preserving patient function. This study focused on physician perception of safety but lacked evaluation of patient function and longitudinal followup. All-inclusive care for patients with chronic noncancer pain should incorporate a patient-centered plan that includes functional assessment and long-term followup. It is our responsibility as Family Medicine physicians to care for the whole patient by promoting a sustainable plan to preserve safety and function.

Allison H. Gase, DO Family Medicine Residency Program OhioHealth Riverside Methodist Hospital

Columbus, $\mathrm{OH}$ allison.gase@ohiohealth.com

To see this article online, please go to: http://jabfm.org/content/ 34/1/243.full.

\section{References}

1. Stack M, LaRouche L, Zhang Y, Warden D, Stack C, Klugiene E. Effects of implementing a comprehensive opioid reduction protocol on overall opioid prescribing among patients with chronic, non-cancer pain in a rural family medicine clinic: a controlled crossover trial. J Am Board Fam Med 2020;33:502-11.

2. Moss C, Bossano C, Patel S, Powell A, Chan Seay R, Borahay MA. Weaning from long-term opioid therapy. Clin Obstet Gynecol 2019;62:98-109.

3. Tan G, Jensen MP, Thornby JI, Shanti BF. Validation of the brief pain inventory for chronic nonmalignant pain. J Pain 2004;5:133-137.

4. Derefinko KJ, Salgado Garcia FI, Talley KM, et al. Adverse childhood experiences predict opioid relapse during treatment among rural adults. Addict Behav 2019; 96:171-4.

doi: $10.3122 / j a b f m .2021 .01 .200420$

\section{Response: Re: Effects of Implementing a Comprehensive Opioid Reduction Protocol on Overall Opioid Prescribing Among Patients with Chronic, Non-Cancer Pain in a Rural Family Medicine Clinic: A Controlled Crossover Trial}

To the Editor: We appreciate Dr. Gase's drawing attention to the patient's experience during opioid reduction. We agree with the importance of functional assessment, longitudinal followup, * and treating the whole person. However, we believe that Dr. Gase, and the medical community in general, have not gone nearly far enough in our advocacy for patients with chronic noncancer pain. We would like to illustrate with 2 patients from our original intervention group who we continue to see clinically.

Betty is a 47-year old female ${ }^{\dagger}$ who was in our original intervention group. When she first came to us, she was on 438 Morphine Milligram Equivalents (MME) and Xanax TID. In the context of a trusted family medicine relationship, she talked about her childhood experiences. At age 8 years she frequently stood between her stepfather and her 2 younger brothers, taking his violent blows intended for them. Her mother stood by encouraging the stepfather to "teach them a lesson." At night, Betty would lie awake in bed, hearing her mother drive away to work the night shift and then her father's footsteps coming down the hall toward her bedroom.

At a recent appointment, Betty was excited to share a tape recording of her courageously confronting her now elderly stepfather for the first time about the truth of his physical and sexual violence. Betty is off benzodiazepine and is on 22.5 MME. 